\title{
Effects of Voluntary Activities Motivation of the Youths on the Development of Citizenship
}

\author{
Min Joo Lee1), Bok Seon Hwang2)
}

\begin{abstract}
In a democratic country, the right citizenship is of paramount importance, especially for youth with suffrage. So, this study examined how demographic characteristics, volunteer period, volunteer time of the youth affects the formation of citizenship. And Voluntary Activities Motivation(self-development motivation, representative motivation, external motivation, leisure motivation) of the youth affect the formation of citizenship(community consciousness, compliance consciousness, equality consciousness). A total of 127 valid responses were obtained and a t-test and one way ANOVA have been performed using the SPSS WIN 21.0 program. The results of the analysis are as follows.As a result, first, the representative motivation ( $\beta$ $=.601, \mathrm{p}<.001)$, the external motivation $(\beta=.168, \mathrm{p}<.05)$, self-development motivation $(\beta=.135, \mathrm{p} .05)$ had a positive $(+)$ effect on the citizen consciousness in order. Second, the representative motivation $(\beta=.972, p$ $<.001)$ and the self-development motivation $(\beta=.086, \mathrm{p}<.05)$ had a positive $(+)$ effect, while the external motivation $(\beta=-.085, p<.05)$ had a negative $(-)$ effect on the citizenship. Third, leisure motivation $(\beta=$. $486, \mathrm{p}<.01)$, self-development motivation $(\beta=.231, \mathrm{p}<.001)$ and representative motivation $(\beta=.217, \mathrm{p}$ $<.001)$ had a positive effect on citizenship. First and foremost, it is necessary to establish a program to make volunteer activities readily available, thus giving youth external motivation to continue participation. Opportunities should be provided for teenagers to do volunteer work related to their interests, in order to provide them with self-development motivation. Options to participate in volunteer activities that are connected with community groups should be available to supply youth with representative motivation. Fourth, to give external motivation, it is suggested to actively provide opportunities to participate in volunteer activities so that youth can continue volunteer activities. Lastly, to give leisure motivation, youth should participate in volunteer activities happily through play.
\end{abstract}

Keywords: Citizenship, Community Spirit, Equality Awareness, Law-abiding Spirit, Volunteer Activities Motivation, Youth Volunteer Activities

\section{Introduction}

In a democratic country, citizenship is particularly important for youth with suffrage.

Received(April 10, 2020), Review Result(1st: June 1, 2020, 2nd: July 13, 2020), Accepted(July 27, 2020)

1) (Student) 10587 Goyang Foreign Language High School, Samsong-dong, Deokyang-gu, Goyang-si, Gyeonggi-do, Korea

email: minj0922@naver.com

2) (Professor, Corresponding Author) 11644 department of administration, Shinhan University. Uijeongbu-si, Gyeonggi-do, Korea

email: god-boksun@hanmail.net 
Cultivating social members with citizenship is also the main goal of social education. Gross and Dynneson (1991)[1] stated that citizenship is not given innately but is learned through education in the home, school, or society. Moreover, the learned citizenship contributed to the role of adulthood. In particular, citizen participation in youth is generally practiced as a volunteer activity. The benefit of youth volunteering has already been proven. Ross (2007)[2] defined citizenship as "to promote community improvement through participation and volunteerism and efforts to improve lives for all citizens." Youniss and Yates (1999)[3] stated that volunteer activities experienced by youth are the best way to develop citizenship. Kim Weon Tae (2001)[4] reported that the more youth perform various social experience activities, the higher their citizenship. Song Bok-im (2002)[5] studied the fact that the experiences of youth volunteer activities, pre-education and satisfaction have a positive effect on democratic citizenship.

This study examined how demographic characteristics, volunteer period, volunteer time of the youth effect the formation of citizenship. And Voluntary Activities Motivation(self-development motivation, representative motivation, external motivation, leisure motivation) of the youth effect the formation of citizenship(community consciousness, compliance consciousness, equality consciousness). Moreover, this study examined the relationship between demographic characteristics, volunteer period, volunteer time and citizenship of youth.

\section{Theoretical Background}

\subsection{Youth Volunteering Concept}

One of the developmental characteristics of adolescence is that it is the period to establish values for oneself. Youth interact with society in earnest with the values created during this time. Volunteering is an activity that is selected freely, without concern for financial gain, out of a sense of social responsibility and under the awareness of specific needs. In addition, the concept has been expanded to include planned and organized social actions for the development and peace of the community (Jo Hwi-il, 2002)[6].

The Korea Social Welfare Council stated that volunteering is an activity where one freely participates in the prevention and resolution of social problems and the promotion of public interest projects, in order to provide necessary services and achieve self-realization of altruism based on democratic principles and respect for humanity. 


\subsection{Citizenship Concept}

Citizenship is a consciousness of democracy, the attitude of life, or the mind of people who constitute civil society. It is the ideology that historically broke the feudal system and established a civil society. Citizenship today refers to the attitude that an individual in society acts with responsibility as an independent human being and speaks from the standpoint of improving his/her life. Moreover, it refers to the consciousness that supports the basis of democracy politically. Therefore, citizenship is not only necessary to modernize life, but is also important in modern mass society.

\subsection{Review of Previous Research}

According to prior studies related to citizenship, Kyung Hwan Mo, Myung Jung Kim and Seong Min Song(2010)[7] found that students who are female, lower grade, living in Seoul, having more executive experience and economic families, getting better grades have higher rates of citizenship.

Jo Ho-un et al. (2012)[8] studied the differences between the impact of volunteer activities on citizen consciousness, positive self-perception, and peer relationships among middle and high school students. As a result, volunteer activities of middle school students did not have a direct effect on their peer relationships; rather they had an indirect effect through the mediums of citizen consciousness and positive self-perception. Kim Hyun-Kyung et al. (2015)[9] set the following as independent variables: human rights respecting school culture, human rights situation, discrimination experience and participation in school management and analyzed their impact on human rights-friendly school culture. As a result, human rights respecting school culture had a statistically significant impact on an adolescent's citizenship consciousness, but the school's human rights situation, discrimination experience and participation in school management had a statistically meaningless impact on youth citizenship.

\section{Research Method}

\subsection{Survey Target}

A first-year student at a foreign language high school in Goyang City conducted the survey with a male to female ratio of 3:7. The survey collected 129 copies of the Likert questionnaire. We used 127 for our analysis, and excluded 2, as they were not sincere in the double response. 


\subsection{Research Tools}

\subsubsection{Motivation for Youth Volunteer Activities}

The scale used by Mi Jung Kwak and Sin Yong Moon (2010)[10] was used to measure the motivation of youth participation in volunteer activities. Therefore, motivation of youth volunteer activities is divided into representative motivation, self-development motivation, leisure motivation, and external motivation. Self-development motivation refers to the motivational skills of improvement, knowledge acquisition, social exchange and network formation in which volunteers aim to strengthen their capabilities, accumulate experiences, and expand interpersonal relationships. Representative motivation reflects the intention to contribute to community development. External motivation is defined as motivation by external influence from close person. It is a motivation related to the consciousness from another's eyes rather than subjective judgment. Lastly, leisure motivation is motivation generated by one's inner interests.

\subsubsection{Citizenship}

\subsubsection{Community Spirit}

Community consciousness is the sense of attribution or bond felt by members of a community. In other words, it is the rights and responsibilities of a societal member in maintaining the community, and more specifically, prioritizing the interests of the community as a whole rather than the interests of the individual. Community consciousness alleviates conflict and indiscriminate competition among members and increases productive cooperation and fair competition for the maintenance and development of the community. In modern society, community consciousness is an important component of citizenship, in that it enables the alienated people of society to recover and fulfill their rights and duties as members of a community, thus achieving social integration. Therefore, it is necessary for youth to develop community consciousness through volunteer activities.

\subsubsection{Law-abiding Spirit}

Chung seong ho(2002)[11] argued that compliance is a basic matter of civic consciousness, and that compliance consciousness should be treated with importance in order for society to develop because society is likely to be confused if it does not observe law and order. In addition, he argues that people's law-abiding spirit of observing basic rules is a significant 
factor for determining whether a country is an advanced country.

The overall atmosphere of Korean society is that it lacks in law-abiding spirit and thus, is gradually getting away from the citizen's interest. This has a negative impact on young people. Therefore, this study will examine the factors that have a positive effect on the cultivation of proper law-abiding spirit through volunteer activities for students who will become the future of society.

\subsubsection{Equality Awareness}

Equality awareness is based on the notion that everyone is born with equal rights and dignity, and that everyone has the right to be treated fairly and justly. The protection and promotion of equality awareness are essential to improving peace, harmony and productivity within the community. Equal awareness is important for the democratic development of Korean society, considering that a horizontal relationship with the attitude to coexist with others is the beginning of equality consciousness.

In Korean society, there are various inequalities due to academic background, job acquisition, gender, foreign workers, and regional imbalance. These disparities have a negative impact on students' equality awareness. Considering that equality awareness is an essential element in solving social inequality, integrating and restoring fairness, the equality awareness of students should be considered important.

\subsection{Data Analysis}

\subsubsection{Validity Analysis}

Exploratory factor analysis was conducted to verify the validity of the measurement tool used in this study. Seven items $(8,9,14,16,21,22,24)$ that hindered the validity of volunteer activity motivation were excluded and factor analysis was conducted with 17 items. As a result of the analysis, KMO was .880 , Bartlett's test of sphere formation was also significant $(\mathrm{p}<.001)$, and the factor analysis model was judged to be appropriate.

Factor classification was considered when factor loading exceeded 0.5, and four factors showed $76.838 \%$ of factor explanation. The motivation for volunteering was classified into four factors. The factors were self-development motivation, representative motivation, external motivation, and leisure motivation.

Next, citizenship was analyzed by factor analysis with 9 items. As a result of the analysis, 
KMO was .802, and Bartlett's test of sphere formation was also significant $(p<.001)$, and the factor analysis model was judged to be appropriate.

\subsubsection{Reliability Verification}

The reliability analysis was conducted to determine whether the respondents responded consistently through the questionnaire. To verify this, Cronbach's alpha coefficient was used. Generally, if the alpha coefficient is 0.6 or higher, it is considered that the reliability is relatively high. The Cronbach's alpha coefficient of all variables is 0.6 or more, which is considered to be highly reliable.

[Table 1] Reliability Verification

\begin{tabular}{llcc}
\hline \multicolumn{1}{c}{ Variable } & \multicolumn{1}{c}{ Sub-factor } & Question & Cronbach's a \\
\hline \multirow{4}{*}{ Voluntary Activities Motivation } & Self-development motivation & 5 & .834 \\
& Representative motivation & 4 & .872 \\
& External motivation & 2 & .762 \\
& Leisure motivation & 4 & .946 \\
\cline { 2 - 4 } & Total & 15 & .852 \\
\hline \multirow{5}{*}{ Citizenship } & Community spirit & 5 & .892 \\
& Law-abiding spirit & 2 & .817 \\
& Equality awareness & 2 & .755 \\
\cline { 2 - 4 } & Total & 9 & .815 \\
\hline
\end{tabular}

\section{Results}

\subsection{Differences in Citizenship According to General Characteristics}

In order to find out whether there is a difference in citizenship according to the general characteristics of the subjects, independent sample t-test, one-way ANOVA, Scheffe, and Tukey were conducted. As a result of the analysis, there was a statistically significant difference in citizenship according to volunteer period and resource time. In the volunteer period $(t=5.359$, $\mathrm{p}<.01)$, the students who volunteered for more than 5 years showed higher citizenship than the students who volunteered for less than 2 years. Regarding volunteer time $(t=3.492, p<.05)$, the students who volunteered for more than 30 hours showed higher citizenship than the students who volunteered for less than 10 hours. 
[Table 2] Differences in citizenship according to general characteristics

\begin{tabular}{|c|c|c|c|c|c|}
\hline Variable & Sortation & $\mathrm{N}$ & $\mathrm{M} \pm \mathrm{SD}$ & $\mathrm{t} / \mathrm{F}$ & $\mathrm{p}$ (Scheffe) \\
\hline \multirow{2}{*}{ Sex } & Male & 26 & $3.089 \pm 0.173$ & \multirow{2}{*}{-.468} & \multirow{2}{*}{.640} \\
\hline & Female & 101 & $3.1649 \pm 0.068$ & & \\
\hline \multirow{3}{*}{ Volunteer Period } & Less than 2 years a & 35 & $2.934 \pm 0.122$ & \multirow{3}{*}{5.359} & \multirow{3}{*}{$\begin{array}{c}.006^{* *} \\
(a<b<c)\end{array}$} \\
\hline & $\begin{array}{l}\text { More than } 2 \text { years - less than } \\
5 \text { years } b\end{array}$ & 83 & $3.167 \pm 0.075$ & & \\
\hline & More than 5 years $\mathrm{c}$ & 9 & $3.149 \pm 0.274$ & & \\
\hline \multirow{3}{*}{ Volunteer Time } & Less than 16 hours a & 33 & $3.008 \pm 0.116$ & \multirow{3}{*}{3.492} & \multirow{3}{*}{$\begin{array}{c}.034^{*} \\
(\mathrm{a}<\mathrm{c}) \\
\text { Tukey } \\
\text { verification }\end{array}$} \\
\hline & $\begin{array}{l}\text { More than } 17 \text { hours - less } \\
\text { than } 30 \text { hours } b\end{array}$ & 52 & $3.0771 \pm 0.108$ & & \\
\hline & More than 30 hours $c$ & 42 & $3.401 \pm 0.095$ & & \\
\hline \multirow{4}{*}{ Major } & English & 57 & $3.195 \pm 0.094$ & \multirow{4}{*}{.363} & \multirow{4}{*}{.780} \\
\hline & Chinese & 20 & $3.125 \pm 0.145$ & & \\
\hline & Japanese & 27 & $3.187 \pm 0.107$ & & \\
\hline & Spanish & 23 & $3.149 \pm 0.064$ & & \\
\hline
\end{tabular}

${ }^{*} \mathrm{p}<.05 * * \mathrm{p}<.01$

\subsection{Effect of Volunteer Activity Motivation on Citizenship}

\subsubsection{The Effect of Volunteer Activity Motivation on the Community Spirit of Citizenship}

In order to verify the effect of youth volunteer activity motivation on citizenship, multiple regression analysis was conducted using general characteristics such as volunteer period and volunteer time as control variables. As a result of verifying the regression model, the regression model was suitable with $\mathrm{F}=53.002(\mathrm{p}<.001)$, and the explanatory power of the model was about $72.6 \%$. The Durbin-Watson statistics were 1.653 , which was close to 2 , so there was no problem with the independence assumption of the residuals, and the variance inflation factor (VIF) was less than 10, which did not show any multicollinearity problems.

As a result of the significance verification of the regression coefficient, self-development motivation, representative motivation, and external motivation had significant positive effects on the sense of community of citizen consciousness, even when controlled by general characteristics. In other words, the higher the self-development motivation, representative motivation, and external motivation of volunteer activities, the higher the citizenship. Representative motivation $(\beta=.601, \quad \mathrm{p}<.001)$, external motivation $(\beta=.168, \mathrm{p}<.05)$, and self-development motivation $(\beta=.135, p<.05)$ were found to affect citizenship, while leisure 
motivation had a meaningless effect on the community consciousness of citizenship $(p>.05)$.

[Table 3] The Effect of Volunteer Activity Motivation on the Community Spirit of Citizenship

\begin{tabular}{ccccccc}
\hline Independent Variable & $\mathrm{B}$ & $\mathrm{S} . \mathrm{E}$ & $\beta$ & $\mathrm{t}$ & $\mathrm{p}$ & $\mathrm{VIF}$ \\
\hline Constant & 0.919 & 0.15 & & 6.141 & 0 & \\
Volunteer Period & 0.076 & 0.057 & 0.071 & 1.332 & 0.186 & 1.223 \\
Volunteer Time & -0.026 & 0.041 & -0.034 & -0.635 & 0.527 & 1.231 \\
\hline Self-development & 0.099 & 0.055 & 0.135 & 1.799 & 0.075 & 2.422 \\
Representative Motivation & 0.457 & 0.048 & 0.601 & 9.438 & 0.000 & 1.743 \\
External Motivation & 0.104 & 0.044 & 0.168 & 2.384 & 0.019 & 2.134 \\
Leisure Motivation & 0.051 & 0.044 & 0.082 & 1.165 & 0.247 & 2.125 \\
\hline
\end{tabular}

$\mathrm{F}=53.002(\mathrm{p}<.001), \mathrm{R} 2=.740$, adjusted $\mathrm{R} 2=.726$, Durbin-Watson=1.653

${ }^{*} \mathrm{p}<.05^{* * *} \mathrm{p}<.001$

\subsubsection{The Effect of Volunteer Activity Motivation on the Law-abiding Spirit of Citizenship}

In order to verify the effect of youth volunteer activity motivation on citizenship, multiple regression analysis was conducted using general characteristics such as age, volunteer activity period, volunteer activity time, and department as control variables.

As a result of verifying the regression model, the regression model was suitable with $\mathrm{F}=243.365(\mathrm{p}<.001)$, and the explanatory power of the model was about 92.5\%. Durbin-Watson statistics were 1.844 , which was close to 2 , so there was no problem with the independence assumption of the residuals, and the variance inflation factor (VIF) was less than 10, which did not show multicollinearity problems.

As a result of the significance verification of the regression coefficient, self-development motivation and representative motivation were found to have a significant positive effect on law-abiding spirit, even when controlled by general characteristics. But external motivation had a significant negative effect on the law-abiding spirit of citizenship. In other words, higher self-development motivation and representative motivation for volunteer activities, the higher the citizenship, but the higher the external motivation, the lower the citizenship. Representative motivation (=.972, $\mathrm{p}<.001)$, self-development motivation $(=.086, \mathrm{p}<.05)$, and external motivation $(=-.085, \mathrm{p}<.05)$ were found to affect the citizenship consciousness respectively, while leisure motivation had a meaningless effect on the law-abiding spirit of citizenship ( $p>.05)$. 
[Table 4] The Effect of Volunteer Activity Motivation on the Law-abiding Spirit of Citizenship

\begin{tabular}{lcccccc}
\hline Independent Variable & $\mathrm{B}$ & $\mathrm{S} . \mathrm{E}$ & $\beta$ & $\mathrm{t}$ & $\mathrm{p}$ & $\mathrm{VIF}$ \\
\hline Constant & .018 & .111 & & .166 & .868 & \\
Volunteer Period & .002 & .042 & .002 & .055 & .956 & 1.223 \\
Volunteer Time & .028 & .031 & .025 & .905 & .368 & 1.231 \\
\hline Self-development & .089 & .041 & .086 & 2.182 & .031 & 2.422 \\
Representative Motivation & 1.047 & .036 & .972 & 29.202 & .000 & 1.743 \\
External Motivation & -.075 & .032 & -.085 & -2.299 & .023 & 2.134 \\
Leisure Motivation & -.058 & .032 & -.066 & -1.799 & .075 & 2.125 \\
\hline
\end{tabular}

$\mathrm{F}=243.365(\mathrm{p}<.001), \mathrm{R} 2=.929$, adjusted $\mathrm{R} 2=.925$, Durbin-Watson=1.844

${ }^{*} \mathrm{p}<.05{ }^{* * *} \mathrm{p}<.001$

\subsubsection{The Effect of Motivation for Volunteer Activities on Equality Spirit of Citizenship}

As a result of verifying the regression model, the regression model was suitable with $\mathrm{F}=46.282(\mathrm{p}<.001)$, and the explanatory power of the model was about $69.7 \%$. Durbin-Watson statistics were 2.118, which was close to 2 , so there was no problem with the independence assumption of the residuals, and the variance inflation factor (VIF) was less than 10, which did not show multicollinearity problems.

As a result of the significance verification of the regression coefficient, self-development motivation, representative motivation, and leisure motivation had a significant positive effect on the equality awareness of citizenship, even when controlled by general characteristics. In other words, the higher the self-development motivation, representative motivation, and leisure motivation for volunteer activities, the higher the citizenship. Leisure motivation $(=.486, \mathrm{p}<.01)$, self-development motivation $(=.231, \mathrm{p}<.001)$, and representative motivation $(=.217, \mathrm{p}<.001)$ were found to affect citizenship respectively, while external motivation had a meaningless effect on equality awareness of the citizenship( $\mathrm{p}>$.05).

[Table 5] The Effect of Motivation for Volunteer Activities on Equality Spirit of Citizenship

\begin{tabular}{lcccccc}
\hline Independent Variable & $\mathrm{B}$ & $\mathrm{S} . \mathrm{E}$ & $\beta$ & $\mathrm{t}$ & $\mathrm{p}$ & $\mathrm{VIF}$ \\
\hline Constant & -.443 & .262 & & -1.693 & .093 & \\
Volunteer Period & .160 & .100 & .090 & 1.604 & .112 & 1.223 \\
Volunteer Time & -.056 & .073 & -.043 & -.768 & .444 & 1.231 \\
\hline Self-development & .283 & .097 & .231 & 2.934 & .004 & .413 \\
Representative Motivation & .274 & .085 & .217 & 3.241 & .002 & .574 \\
External Motivation & .045 & .077 & .044 & .591 & .555 & .469 \\
Leisure Motivation & .505 & .077 & .486 & 6.584 & .000 & .471 \\
\hline
\end{tabular}

$\mathrm{F}=46.282(\mathrm{p}<.001), \mathrm{R} 2=.713$, adjusted $\mathrm{R} 2=.697$, Durbin-Watson=2.118

${ }^{*} p<.05{ }^{* * *} p<.001$ 


\section{Conclusion}

This study aimed to explore various ways to improve the citizenship of high school students by empirically analyzing the effects of volunteer activities on youth citizenship. The results of this study are summarized as follows: First, the period of volunteering and volunteering time among the demographic characteristics were significant. Students with long volunteer periods showed higher citizenship and students with long volunteer times also had higher citizenship. Furthermore, it was found that self-development motivation, representative motivation, and external motivation of volunteer activities all had a positive effect on the community spirit of citizenship. Self-development motivation, representative motivation, and external motivation of volunteer activities had positive effects on the law-abiding spirit of citizenship. Additionally, the study showed that self-development motivation, representative motivation, and leisure motivation of volunteer activities had positive effects on the equality consciousness of citizenship.

This study examined the effects of youths' volunteer activities on their citizenship and suggested the following ways to increase motivation to perform volunteer activities, which would in turn increase citizenship. First, students who had a longer volunteering period and volunteering time had higher citizenship. Therefore, it is necessary to establish a program that allows students to continue volunteering. The positive recognition of volunteer activities, high support of family, and the support of a club have a significant effect on the will to continue volunteer work (Park Jeong-nam, 2009)[12]. Volunteer activities should be available through a project-type program that consists of several times, not one-off activities, so that one can participate continuously. Secondly, it is necessary to provide opportunities for young people to volunteer in areas that appeal to them, so that they can stay motivated to continue. In order to have representative motivation, opportunities to participate in volunteer activities connected with community organizations are necessary. This can have a positive effect on community spirit, law-abiding spirit, and equality awareness of citizenship. Furthermore, it is suggested that volunteer activities should be provided actively so that they can be continued in order to give external motivation. Finally, to give leisure motivation, youth should participate in volunteering happily, so it can have a positive effect on the equality awareness of citizenship. By positively motivating young people to volunteer, they will be able to grow into democratic citizens with healthy citizenship in the future. Factors affecting the formation of civic awareness should be continuously studied to enhance the civic awareness of teenagers. 


\section{References}

[1] Gross, R. E., Dynneson, T. L., Social Science Perspectives on Citizenship Education, USA: Teachers College Press, (1991)

[2] Ross, A., Multiple Identities and Education for Active Citizenship, British Journal of Education Studies, (2007), Vol.55, No.3, p.286.

[3] Youniss J, Yates M., Adolescents' Public Discussion and Collective Identity, Verbal and Nonverbal Facets of Communication: Social Interaction, Cultural Practices, and Development, USA: Lawrence Erlbaum Associates, (2000)

[4] Kim Weon Tae, The effects of the experience in social participation on the citizenship in the high school, Theory and Research in Citizenship Education, (2001), Vol.33, pp.49-88.

[5] Song Bok Im, The impact of youth volunteering on the development of democratic citizenship Research, Dong-A University, Master's thesis,,(2002)

[6] Jo Hwi-il, Modern Society and Volunteering, Korea: Hong-Ik-jae, (2002)

[7] Kyung Hwan Mo, Myung Jung Kim, Seong Min Song, Research Paper: Research on Citizens' Awareness of Korean Youth, Citizen Education Research, (2010), Vol.42, No.1, pp.77-101.

[8] Jo Ho Woon, Jo Soung Hwan, Kim Yeong Hee, The Effects of Youth's Volunteer Activities on Citizenship, Positive Self-Perception, and Peer Relationships, Journal of the Korean Society of Human Ecology, (2012), Vol.21, No.4, pp.729-744.

[9] Hyoun Gyoung Kim, Shin Young Kim, The Effect of Human Rights-Friendly School Culture on Youth's Citizenship Consciousness, Citizenship Education Research, (2015), Vol.47, No.2, pp.29-52.

[10] Mi Jung Kwak, Sin Yong Moon, A Study on Impact Factors of Civil Consciousness : Focusing on Youths' Participation to Voluntary Activities, Career Maturity and Stres, Career Maturity and Stress, Civil Society \& NGO, (2010), Vol.8, No.2, pp.111-141

[11] Chung Sung-Ho, The Contemporary Problems of Civil Consciousness in Korea, Institute of Social Science, (2002), Vol.41, pp.147-164.

[12] Jeong-nam Park, A Study on the Factors Influencing the Continuity of Volunteer Activities by Adolescents, Daegu University, Master's Thesis, (2009) 